\title{
Role of MDA5 in regulating CXCL10 expression induced by TLR3 signaling in human rheumatoid fibroblast-like synoviocytes
}

\author{
Tatsuro Saruga $^{1}$ (D) Tadaatsu Imaizumi ${ }^{2} \cdot$ Shogo Kawaguchi $^{2} \cdot$ Kazuhiko Seya $^{2} \cdot$ Tomoh Matsumiya $^{2} \cdot$ Eiji Sasaki $^{1}$. \\ Norihiro Sasaki ${ }^{1} \cdot$ Ryoko Uesato $^{1} \cdot$ Yasuyuki Ishibashi ${ }^{1}$
}

Received: 3 September 2020 / Accepted: 4 December 2020 / Published online: 2 January 2021

(c) The Author(s) 2021

\begin{abstract}
C-X-C motif chemokine 10 (CXCL10) is an inflammatory chemokine and a key molecule in the pathogenesis of rheumatoid arthritis (RA). Melanoma differentiation-associated gene 5 (MDA5) is an RNA helicase that plays a role in innate immune and inflammatory reactions. The details of the regulatory mechanisms of CXCL10 production and the precise role of MDA5 in RA synovitis have not been fully elucidated. The aim of this study was to examine the role of MDA5 in regulating CXCL10 expression in cultured human rheumatoid fibroblast-like synoviocytes (RFLS). RFLS was stimulated with Toll-like receptor 3 (TLR3) ligand polyinosinic:polycytidylic acid (poly I:C), a synthetic double-stranded RNA mimetic. Expression of interferon beta $(I F N-\beta), M D A 5$, and $C X C L 10$ was measured by real-time quantitative reverse transcription polymerase chain reaction (qRT-PCR), western blotting, and enzyme-linked immunosorbent assay. A neutralizing antibody of IFN- $\beta$ and siRNA-mediated MDA5 knockdown were used to determine the role of these molecules in regulating CXCL10 expression downstream of TLR3 signaling in RFLS. Poly I:C induced IFN- $\beta$, MDA5, and CXCL10 expression in a concentration- and time-dependent manner. IFN- $\beta$ neutralizing antibody suppressed the expression of MDA5 and CXCL10, and knockdown of MDA5 decreased a part of CXCL10 expression $(p<0.001)$. The TLR3/IFN- $\beta / C X C L 10$ axis may play a crucial role in the inflammatory responses in RA synovium, and MDA5 may be partially involved in this axis.
\end{abstract}

Keywords CXCL10 $\cdot$ IFN- $\beta \cdot$ MDA5 $\cdot$ Rheumatoid arthritis $\cdot$ TLR3

\section{Introduction}

Rheumatoid arthritis (RA) is a common chronic inflammatory autoimmune disease that reduces quality of life [1]. The incidence of RA is considered to $0.5 \%$ to $1.0 \%$ in the world $[2,3]$. Common characteristics of RA include infiltration of macrophages and lymphocytes, synovitis, and destruction of bone and cartilage [4]. An essential step in the pathogenesis of RA is the infiltration of the synovium by immune cells, which causes synovitis [5]. Thus, the fibroblast-like synoviocytes are critical cells in the pathogenesis of RA

Tatsuro Saruga

suntatsurous@hirosaki-u.ac.jp

1 Department of Orthopaedic Surgery, Hirosaki University Graduate School of Medicine, 5 Zaifu-cho, Hirosaki 036-8562, Japan

2 Department of Vascular Biology, Hirosaki University Graduate School of Medicine, 5 Zaifu-cho, Hirosaki 036-8562, Japan because these cells produce pro-inflammatory cytokines and proteases that contribute to cartilage destruction [6].

The innate immune system is the first line of protection against pathogenic microorganisms. The innate immune system is activated by pattern-recognition receptors that recognize pathogen-associated molecular patterns (PAMPs). In addition to PAMPs, damage-associated molecular patterns (DAMPs) released from dead and/or stressed cells can be also recognized by pattern-recognition receptors. DAMPs may induce sterile inflammation in the absence of infection and plays an important role in the pathogenesis of autoimmune diseases [7].

Toll-like receptors (TLRs) are the major pattern recognition receptors, and TLR3 is a receptor for double-stranded RNA (dsRNA). TLR3 is expressed in RA synoviocytes, and activation of TLR3 signaling induces the expression of various cytokines including vascular endothelial growth factor, interleukin-8 [8], C-C motif chemokine ligand 5 and C-X-C motif chemokine ligand 10 (CXCL10) [9]. The expression of TLR3 is reported to be higher than TLR2 and TLR4 in 
synovial fibroblasts [10]. Synovial inflammation may lead to the production of DAMPs in joints of patients with RA, and RNA released from necrotic synovial cells may activate TLR3 signaling in synoviocytes [11].

IFN- $\beta$, a type I IFN, is a key cytokine in innate immune reactions and exerts various functions by inducing the expression of hundreds of IFN-stimulated genes (ISGs). Melanoma differentiation-associated gene 5 (MDA5) is an ISG and was originally identified as a gene that was induced by IFN- $\beta$ in melanoma cells [12]. MDA5 encodes a DExH box RNA helicase that functions as an ATPase [12], an inhibitor of melanoma growth [12], a cytosolic receptor for dsRNA generated during viral replication $[13,14]$, and a signaling molecule that regulates inflammatory reactions [15]. Although MDA5 is reported to be expressed in synovial fibroblasts [8], its precise role in RA synovitis has yet to be elucidated. Viral infections are known to exacerbate joint inflammation of RA [16]. In addition, higher levels of dsRNA were detected in synovial fluid of RA patients than osteoarthritis patients [17]. dsRNA is thought to be highly relevant to the pathogenesis of RA as DAMPs or PAMPs. Therefore, it is important to elucidate the role of TLR3 and MDA5.

CXCL10, also named interferon (IFN)-gamma-inducible protein-10, was initially identified as a chemokine secreted by several cell types including macrophages, endothelial cells, and fibroblasts in response to IFN- $\gamma$ [9]. CXCL10 and IFN- $\gamma$ mediate Th1 type immune reactions [18]. CXCL10 induces chemotaxis of CXC receptor 3 (CXCR3)+ leukocytes, including $\mathrm{T}$ cells and NK cells, and these leukocytes secrete cytokines that stimulate the expression of CXCL10 from other types of cells such as fibroblasts and endothelial cells. Thus, the CXCL10-CXCR3 axis regulates inflammatory responses and is involved in the pathogenesis of autoimmune diseases, such as RA and systemic lupus erythematosus [19]. However, details of the regulatory mechanisms of CXCL10 production in rheumatoid synoviocytes have not been fully elucidated.

The rationale for this study is that, in RA, the roles of TLR3 and MDA5 for synovitis and the regulation of CXCL10 are not well understood. We hypothesized that TLR3 and MDA5 are involved in the regulation of CXCL10 expression. The goal of this study was to investigate this hypothesis using cultured human rheumatoid fibroblast-like synoviocytes (RFLS).

\section{Materials and methods}

\section{Reagents}

Polyinosinic-polycytidylic acid (poly I:C; P1530) and rabbit anti-actin antibody were purchased from Sigma (St.
Louis, MO). FBS was obtained from BIOWEST (Nuaille, France). Human type I interferon neutralizing antibody mixture (39000-1) was purchased from PBL Assay Science (Piscataway, NJ, USA). Small interfering RNA (siRNA) against MDA5 (SI03649037) and validated non-silencing negative control siRNA (1027281) were from Qiagen (Hilden, Germany). Lipofectamine RNAi-MAX reagent and M-MLV reverse transcriptase were from ThermoFisher (Carlsbad, CA, USA). The NucleoSpin RNA isolation kit was purchased from Macherey-Nagel (Duren, Germany). SsoAdvanced Universal SYBR Green Supermix was from Bio-Rad (Hercules, CA, USA). Primer oligo(dT)18 and oligonucleotide primers for polymerase chain reaction (PCR) were synthesized by Greiner Japan (Atsugi, Japan). A rabbit polyclonal antibody against MDA5 was from ImmunoBiological Laboratories (Fujioka, Japan). An enzyme-linked immunosorbent assay (ELISA) kit for CXCL10 was from R $\&$ D Systems (Minneapolis, MN, USA).

\section{Cells}

Human RFLS cells from a patient were purchased from the Health Science Research Resources Bank (Sennan, Japan). This study has been approved by the Ethical Committee of Hirosaki University Graduate School of Medicine (20181117). The cells were cultured in Dulbecco's modified Eagle medium (DMEM) supplemented with $10 \%$ fetal bovine serum. The cells were treated with $0.08-50 \mu \mathrm{g} / \mathrm{mL}$ poly $\mathrm{I}: \mathrm{C}$, and were incubated for up to $24 \mathrm{~h}$. When we perform the experiments using the human type I IFN neutralizing antibody mixture, cells were pre-incubated for $1 \mathrm{~h}$ with the antibody mixture (1:25) and stimulated with $30 \mu \mathrm{g} / \mathrm{mL}$ poly $\mathrm{I}: \mathrm{C}$ for $16 \mathrm{~h}$. In order to observe the effect of MDA5 knockdown, cells were transfected with siRNA against MDA5 or non-silencing control siRNA using Lipofectamine RNAiMAX reagent according to the supplier's protocol. After a 48 -h incubation, $30 \mu \mathrm{g} / \mathrm{mL}$ poly I:C was added to the cells.

\section{RNA extraction, reverse transcription and quantitative real-time PCR}

RNA was extracted, and quantitative reverse transcription-PCR (qRT-PCR) was performed to measure $I F N-\beta$, $M D A 5, C X C L 10$, and glyceraldehyde-3-phosphate dehydrogenase $(G A P D H)$ mRNA expression. Briefly, RNA was reverse transcribed using M-MLV reverse transcriptase and oligo(dT) 18 primer. Amplification of cDNA was performed with gene-specific primers (Table 1) and SsoAdvanced Universal SYBR Green Supermix. GAPDH was used as an internal control. The data of $M D A 5 / G A P D H$ were shown as fold increase compared with unstimulated cells. $I F N-\beta$ and CXCL10 mRNA were not detected in unstimulated cells, 
Table 1 Oligonucleotide primers for quantitative real-time PCR

\begin{tabular}{ll}
\hline cDNA & Sequences \\
\hline CXCL10-F & 5'-TTCAAGGAGTACCTCTCTCTAG-3' \\
CXCL10-R & 5'-CTGGATTCAGACATCTCTTCTC-3' \\
GAPDH-F & 5'-GCACCGTCAAGGCTGAGAAC-3' \\
GAPDH-R & 5'-ATGGTGGTGAAGACGCCAGT-3' \\
IFN- $\beta-F$ & 5'-CCTGTGGCAATTGAATGGGAGGC-3' \\
IFN- $\beta-R$ & 5'-CCAGGCACAGTGACTGTACTCCTT-3' \\
MDA5-F & 5'-GTTGAAAAGGCTGGCTGAAAAC-3' \\
MDA5-R & 5'-TCGATAACTCCTGAACCACTG-3' \\
\hline
\end{tabular}

and the results of $I F N-\beta$ and $C X C L 10 / G A P D H$ were shown as arbitrary units.

\section{Western blotting}

After the incubation, cells were washed and lysed with Laemmli sample buffer. Then, lysates were applied to polyacrylamide gel electrophoresis, and proteins were transferred onto polyvinylidene fluoride membranes. The membranes were blocked, and incubated with a rabbit antibody against MDA5 (1:2000) or actin (1:3000) for $16 \mathrm{~h}$. Subsequently, the membranes were plobed with horseradish peroxidase (HRP)conjugated anti-rabbit IgG antibody. Chemiluminescent for HRP substrate was used to detect the protein bands.

\section{ELISA}

The cells conditioned medium were corrected, and determined using a commercially available ELISA kit according to the manufacturer's protocol.

\section{Statistics}

Data input and calculations were performed with SPSS ver. 12.0 J (SPSS Inc., Chicago, IL, USA). All experiments were performed at least three times. Values are reported as means \pm standard deviation (SD). Differences between groups were analyzed using unpaired $t$-test. $P$ value below 0.05 was considered statistically significant.

\section{Results}

\section{Poly I: $C$ induces the expression of IFN- $\beta$, MDA5, and CXCL10 in RFLS}

Treatment of RFLS with poly I:C resulted in the induction of IFN- $\beta, M D A 5$, and CXCL10 in a concentration- (Fig. 1) and time-dependent manner (Fig. 2). By stimulation with poly $\mathrm{I}: \mathrm{C}, I F N-\beta$ mRNA expression increased rapidly, reached its highest level after $4 \mathrm{~h}$, and quickly decreased (Fig. 2a, upper panel). MDA5 mRNA expression increased after IFN- $\beta$ and peaked at $16 \mathrm{~h}$ (Fig. 2a, middle panel). CXCL10 expression also reached its maximum at $16 \mathrm{~h}$ (Fig. 2a, lower panel). MDA5 (Fig. 2b) and CXCL10 (Fig. 2c) protein expression was also highest at $16 \mathrm{~h}$.

\section{IFN- $\beta$ mediates poly I:C-induced expression of MDA5 and CXCL10}

Pretreatment of cells with neutralizing anti-IFN antibody mixture significantly decreased the induction of MDA5 and CXCL10 mRNA (Fig. 3a). MDA5 (Fig. 3b) and CXCL10 protein (Fig. 3c) expression was also inhibited by the antiIFN antibody mixture.

\section{MDA5 is involved in poly l:C-induced CXCL10 expression}

siRNA-mediated knockdown of MDA5 significantly diminished CXCL10 mRNA (Fig. 4a) and protein (Fig. 4b) expression induced by poly I:C. MDA5 knockdown was confirmed with western blot (Fig. 4c).

\section{Discussion}

We have demonstrated that the activation of TLR3 signaling in RFLS upregulated IFN- $\beta$, MDA5, and CXCL10 expression. In addition, neutralization of IFN- $\beta$ inhibited MDA5 and CXCL10 expression, and knockdown of MDA5 decreased a part of expression of CXCL10. This suggests that TLR3 signaling induces IFN- $\beta$ expression, and newly synthesized IFN- $\beta$ mediates the expression of CXCL10 at least in part via MDA5 in RFLS. Taken together, the TLR3/ IFN- $\beta$ /CXCL10 axis may be involved in the inflammatory response of rheumatoid synovitis, and may be partially mediated by MDA5 (Fig. 5).

CXCL10 protein expression is elevated in serum [20] and synovial fluid [21] from patients with RA. In addition, serum CXCL10 expression is associated with better response to abatacept treatment [22]. Inhibition of the CXCL10/CXCR3 axis has been shown to downregulate the infiltration of inflammatory cells, including macrophages and $\mathrm{T}$ cells, into involved joints and to reduce the severity of synovitis and bone and cartilage destruction in animal models of RA [23]. CXCL10 also increases RANKL (receptor activator of NF-kB ligand) expression in CD4+ T cells [23]. Human phase II clinical trials using anti-CXCL10 monoclonal antibody (MDX-1100) in RA patients reported an improvement in response rate [24]. These findings suggest that CXCL10 plays a crucial role 
Fig. 1 Treatment of human rheumatoid fibroblast-like synoviocytes (RFLS) with polyinosinic-polycytidylic acid (poly I:C) induces the expression of interferon beta (IFN- $\beta$ ), melanoma differentiationassociated gene 5 (MDA5), and CXCL10 in a concentrationdependent manner. RFLS were cultured and treated with $0.08-50 \mathrm{mg} / \mathrm{mL}$ poly I:C.

(a) RNA was extracted after 4-h incubation. cDNA was synthesized and IFN- $\beta$, MDA5, CXCL10, or GAPDH cDNA was amplified using quantitative real-time PCR. Expression of IFN- $\beta$, MDA5, and CXCL10 mRNA was normalized with GAPDH. Data for MDA5 was shown as fold increase vs. unstimulated cells. IFN- $\beta$ and CXCL10 mRNA expression was undetectable in unstimulated cells, and the fold increase for IFN- $\beta$ and CXCL10 is shown as arbitrary units. (b) Cells were lysed after 16-h incubation, and lysates were subjected to western blot to detect MDA5 and actin protein expression. (c) Conditioned medium was collected after 24-h incubation, and the concentration of CXCL10 protein in the medium was measured using an ELISA kit. The data in (a) and (c) represent means \pm standard deviation $(n=3)$
A. Real-time PCR
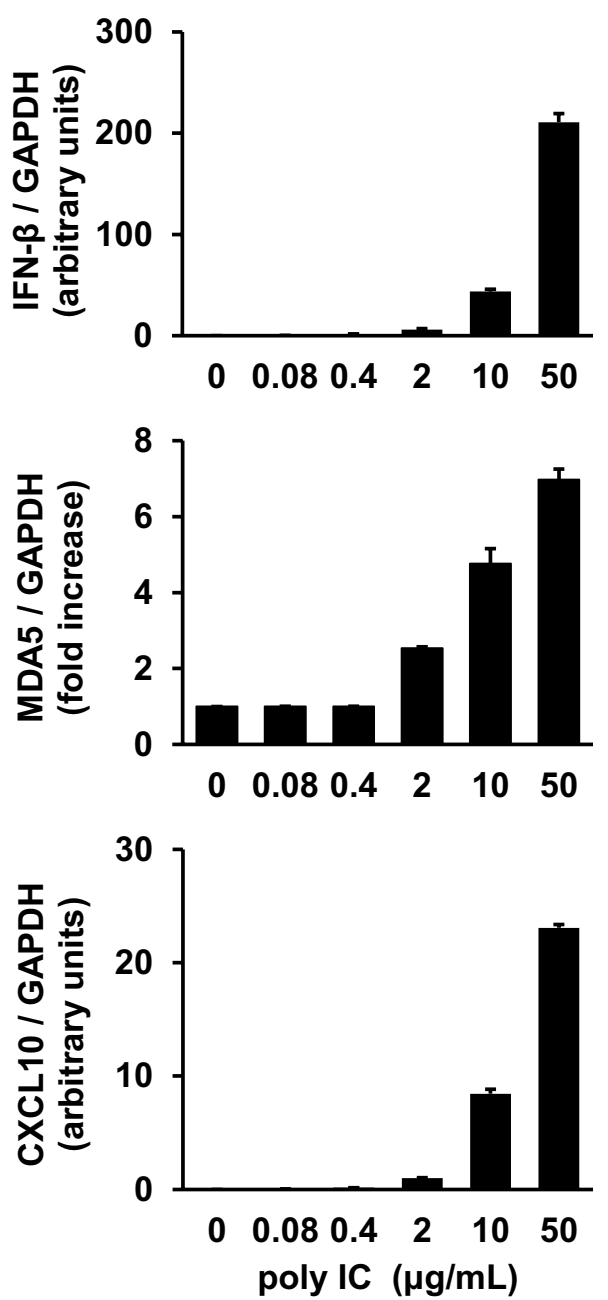

B. Western blotting

MDA5

actin

$\begin{array}{llllll}0 & 0.08 & 0.4 & 2 & 10 & 50\end{array}$

Poly IC $(\mu \mathrm{g} / \mathrm{mL})$

\section{ELISA}

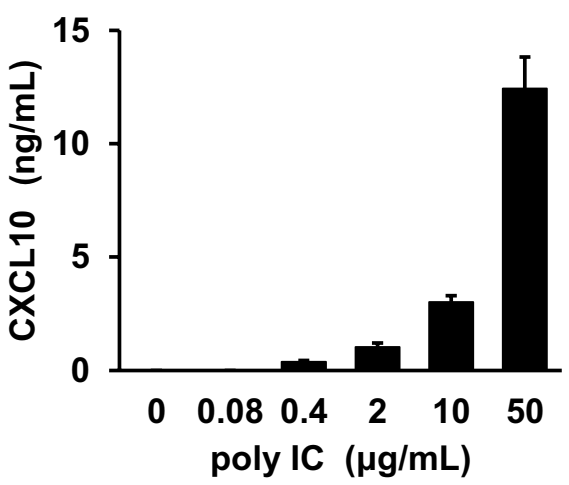

in the pathogenesis of RA, and it is important to clarify the mechanisms by which CXCL10 expression is regulated in RFLS.

The expression of CXCL10 in RFLS is augmented by various stimuli including inflammatory cytokines tumor necrosis factor alpha and IFN- $\gamma$ [25] and TLR3 agonist poly I:C 11]. However, the regulatory mechanisms of CXCL10 production in RFLS have not been fully characterized. The TLR3/IFN- $\beta$ /MDA5/CXCL10 axis demonstrated by our study corroborates previous findings of the role of MDA5 in regulating CXCL10 expression in glomerular mesangial cells [15], brain microvascular endothelial cells [26], and hepatocellular carcinoma cells [27]. The present study revealed a new role of MDA5 in RA synoviocytes and offers new insights about RA sterile inflammation mechanisms. However, the detailed molecular mechanisms by which MDA5 regulates CXCL10 expression should be further investigated.
The results of the present study suggest that IFN- $\beta$ may positively contribute to synovial inflammation downstream of TLR3 signaling. However, this seems to be in contradiction to a previous study which showed that IFN- $\beta$ has a protective effect against joint destruction [28]. IFN- $\beta$ induces the expression of various kinds of ISGs, and ISGs include both pro-inflammatory and anti-inflammatory molecules. We hypothesize that MDA5 and CXCL10 are among the pro-inflammatory ISGs stimulated. The balance of proinflammatory and anti-inflammatory ISGs may be important for regulating inflammation in synoviocytes.

It is known that TLR3 functions as a receptor for poly $\mathrm{I}: \mathrm{C}$ when poly I:C was just added to the culture medium of cells $[15,21,23]$. On the other hand, MDA5 can be a cytosolic RNA receptor when the cells were transfected with poly I:C complexed with cationic-lipid. In the present study, we added poly I:C alone to cells, and it is likely that poly I:C induced down-stream signaling via TLR3. However, 
Fig. 2 Poly I:C induces the expression of IFN- $\beta$, MDA5, and CXCL10 in a timedependent manner. The cells were treated with $30 \mathrm{mg} / \mathrm{mL}$ poly I:C for up to $24 \mathrm{~h}$. (a) RNA was extracted, and IFN- $\beta$, MDA5, CXCL10, and GAPDH expression was measured as in Fig. 1. (b) Cells were lysed, and western blotting for MDA5 and actin was performed. (c) Conditioned medium was collected and the concentration of CXCL10 protein was examined with ELISA. The data in (a) and (c) represent means \pm standard deviation $(n=3)$
A. Real-time PCR
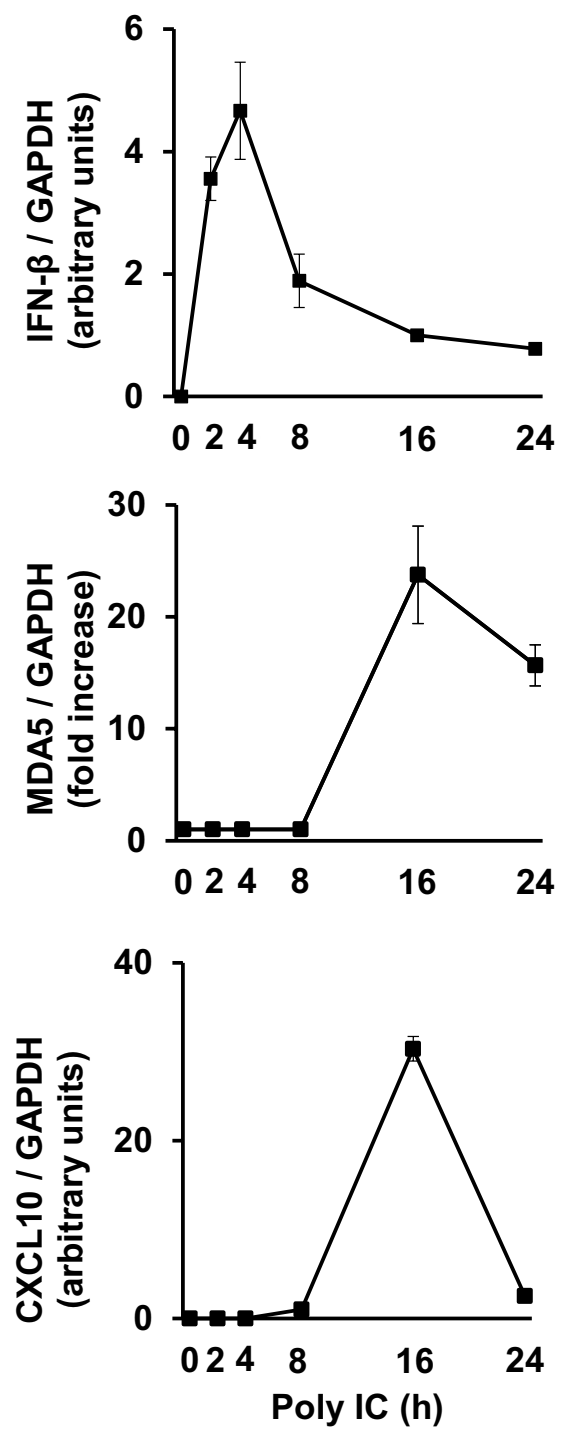

B. Western blotting

MDA5

actin

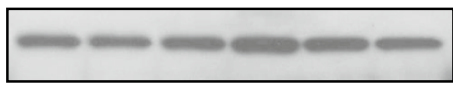

$\begin{array}{llllll}0 & 2 & 4 & 8 & 16 & 24\end{array}$

Poly IC (h)

\section{ELISA}

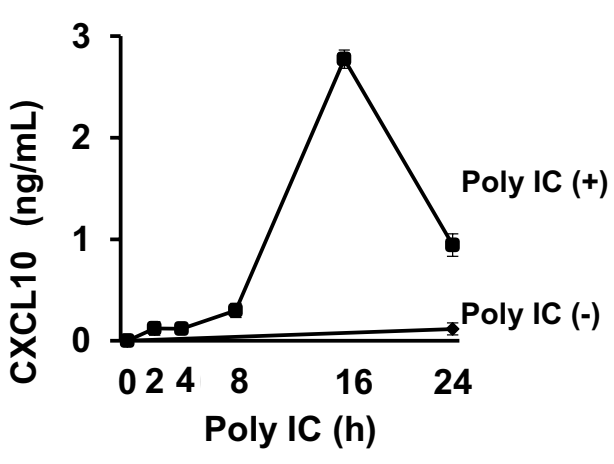

we have not excluded the possibility that poly I:C bound to MDA5. This should be investigated in future studies. The knockdown of MDA5 only partially suppressed the expression of CXCL10. Our results suggest that MDA5 is at least partially involved in CXCL10 expression. The extent to how MDA5 is involved in CXCL10 expression is not clarified in this study, and further studies are required. Because this study was performed using only in vitro culture system, the observation of this study should be confirmed using in vivo model in future study. We showed the possible involvement of MDA5 in CXCL10 expression by dsRNA. CXCL10 produced by intra-articular dsRNA may enhance leukocyte infiltration and exacerbate RA inflammation. If the involvement of MDA5 in RA inflammation is further elucidated, MDA5 would be a new attractive therapeutic target for RA.

\section{Conclusions}

We conclude that activation of TLR3 signaling induces the expression of IFN- $\beta$, MDA5 and CXCL10 in cultured human RFLS. IFN- $\beta$ mediates MDA5 expression which, at least in part, regulates CXCL10 expression. The TLR3/IFN- $\beta$ / CXCL10 axis may play a crucial role in the inflammatory responses in RA synovium, and MDA5 may be partially involved in this axis. 
Fig. 3 Neutralization of IFN- $\beta$ decreases MDA5 and CXCL10 expression induced by poly I:C.

Cells were pre-incubated for $1 \mathrm{~h}$ with human type I IFN neutralizing antibody mixture (1:25 dilution) before being treated with $30 \mathrm{mg} / \mathrm{mL}$ poly I:C for an additional $16 \mathrm{~h}$. (a) RNA was extracted, and qRT-PCR was performed. (b) Cells were lysed, and MDA5 and actin expression was determined with western blot. (c) Medium was collected and subjected to CXCL10 ELISA. The data in (a) and (c) represent means \pm standard deviation $(n=3) .{ }^{*} p<0.01$, by $t$-test

\section{A. Real-time PCR}
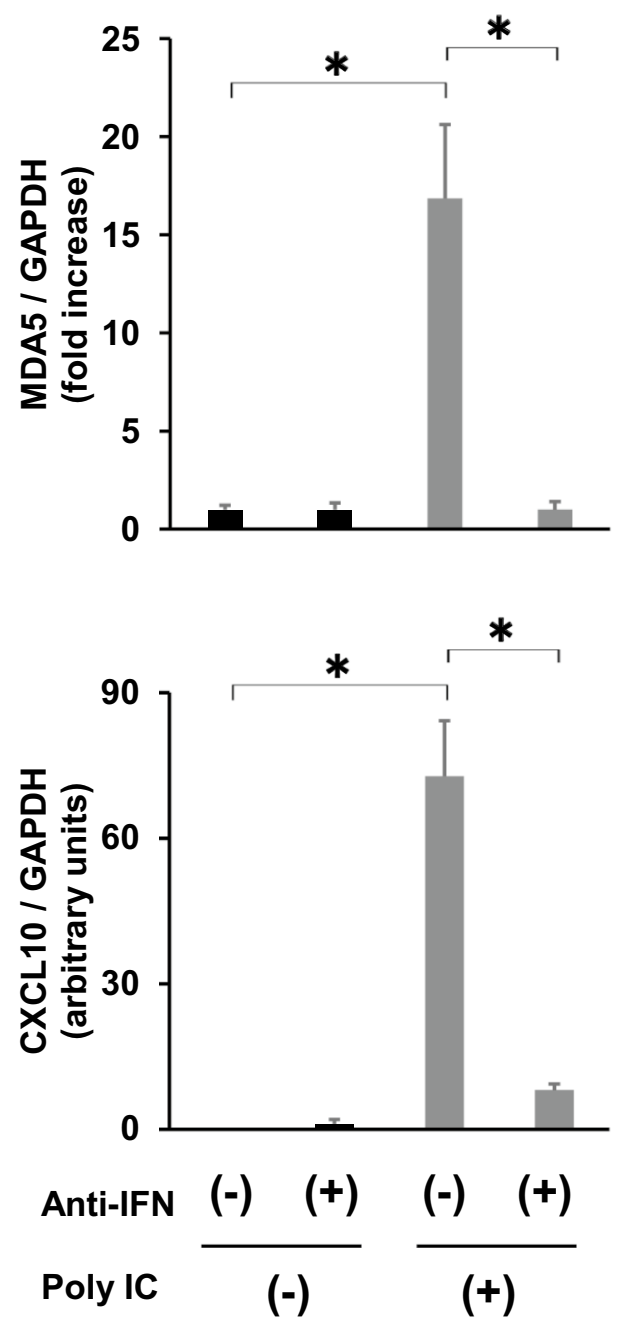

\section{B. Western blotting}

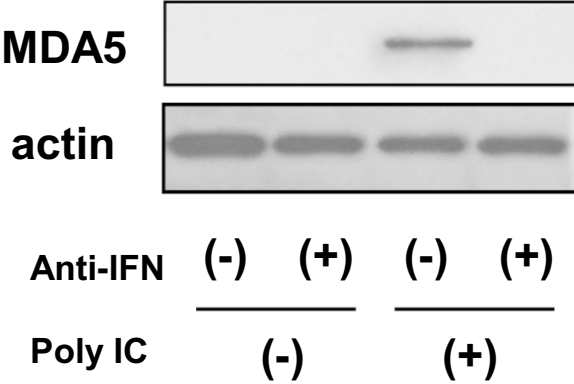

C. ELISA

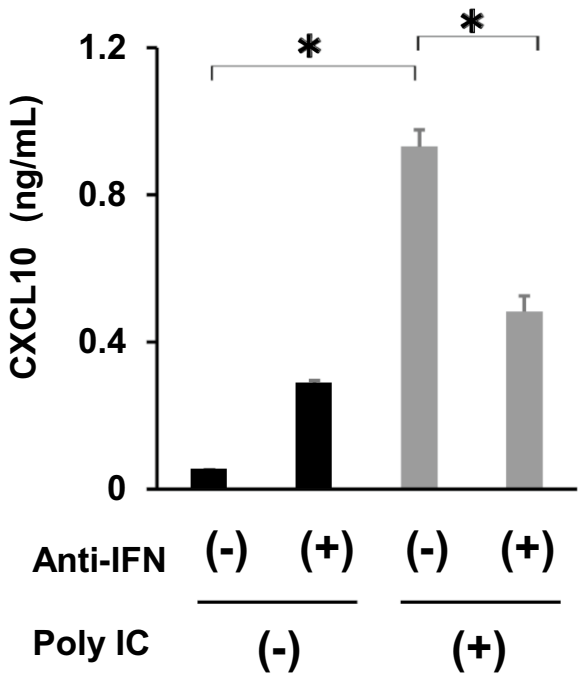


Fig. 4 MDA5 knockdown decreases CXCL10 expression induced by poly I:C. Cells were transfected with a specific small interfering RNA (siRNA) against MDA5 and incubated for $48 \mathrm{~h}$. Then, cells were treated with $30 \mathrm{mg} / \mathrm{mL}$ poly $\mathrm{I}: \mathrm{C}$ for an additional $16 \mathrm{~h}$. (a) RNA was extracted, and mRNA expression was examined using qRT-PCR. (b) Medium was collected and subjected to CXCL10 ELISA. (c) Cells were lysed and subjected to western blot as in Figure 1. Data in (a) and (b) represent means \pm standard deviation $(n=3)$. $* p<0.01$, by $t$-test

\section{A. Real-time PCR}

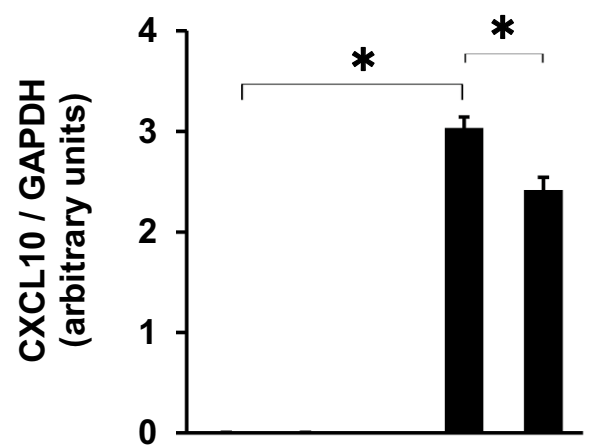

MDA5 SiRNA (-) (+)

Poly IC

$(-)$

B. ELISA
C. Western blotting

MDA5 actin

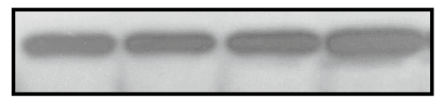

MDA5 SiRNA (-) (+) (-) (+)

Poly IC

(-)

(+)

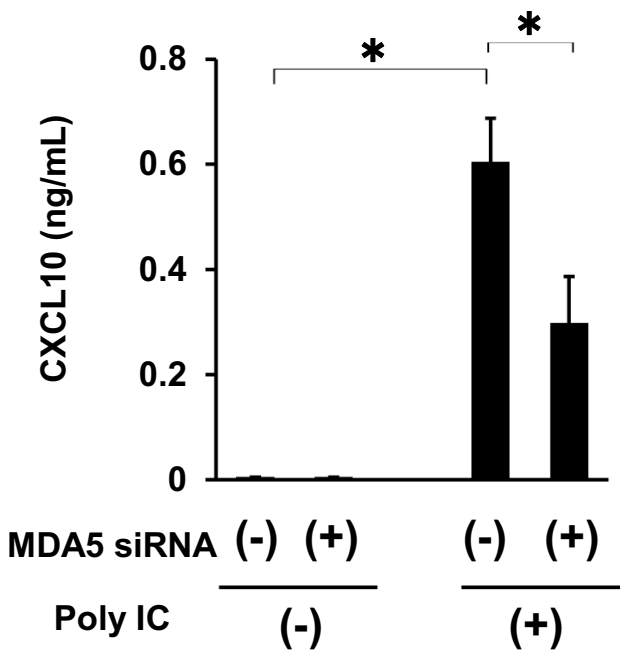


Human rheumatoid fibroblast-like synoviocytes

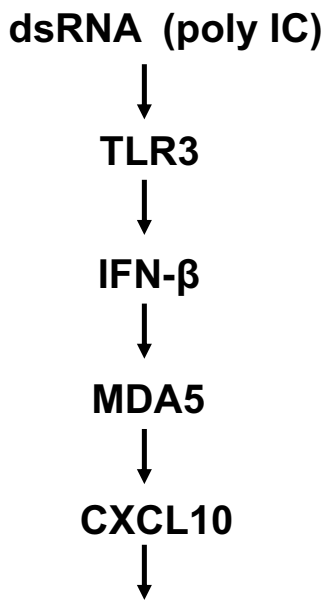

\section{Immune and inflammatory reactions in rheumatoid synoviocytes}

Fig. 5 Proposed signaling pathway of TLR3-mediated CXCL10 expression in human rheumatoid fibroblast-like synoviocytes

Acknowledgements The authors thank Editage (www.editage.com) for English language editing and C.N. for her assistance.

Author contributions TS, TI and YI contributed to the conception and design of the study. TS and TI contributed to the acquisition and the analysis of the data. TS and TI drafted the manuscript. SK, KS, TM, ES, NS and RU revised the manuscript critically for important intellectual content. TS, TI, SK, KS, TM, ES, NS, RU and YI approved the final version of the manuscript to be published. YI is the guarantor. The corresponding author attests that all listed authors meet the authorship criteria and that no other authors meeting the criteria have been omitted.

Funding The authors declare that they have no funding in the study.

Availability of data and material The datasets used and analyzed in the current study are available from the corresponding author on reasonable request.

\section{Compliance with ethical standards}

Conflict of interest The authors declare that they have no competing interest.

Ethical approval This study has been approved by the Ethical Committee of Hirosaki University Graduate School of Medicine (2018-1117).

Consent for publication Consent for publication was not required as no identifying personal information is being published in this manuscript.
Open Access This article is licensed under a Creative Commons Attribution 4.0 International License, which permits use, sharing, adaptation, distribution and reproduction in any medium or format, as long as you give appropriate credit to the original author(s) and the source, provide a link to the Creative Commons licence, and indicate if changes were made. The images or other third party material in this article are included in the article's Creative Commons licence, unless indicated otherwise in a credit line to the material. If material is not included in the article's Creative Commons licence and your intended use is not permitted by statutory regulation or exceeds the permitted use, you will need to obtain permission directly from the copyright holder. To view a copy of this licence, visit http://creativecommons.org/licenses/by/4.0/.

\section{References}

1. Smith JB, Haynes MK (2002) Rheumatoid arthritis-a molecular understanding. Ann Intern Med 136:908-922

2. Silman AJ, Pearson JE (2002) Epidemiology and genetics of rheumatoid arthritis. Arthritis Res 4:265-272

3. Alamanos Y, Voulgari PV, Drosos AA (2006) Incidence and prevalence of rheumatoid arthritis, based on the 1987 American College of Rheumatology criteria: a systematic review. Semin Arthritis Rheum 36:182-188

4. McInnes IB, Schett G (2011) The pathogenesis of rheumatoid arthritis. N Engl J Med 365:2205-2219

5. Batrok B, Firestein GS (2010) Fibroblast-like synoviocytes: key effector cells in rheumatoid arthritis. Immunol Rev 233:233-255

6. Müller-Ladner U, Kriegsmann J, Franklin BN, Matsumoto S, Geiler T, Gay RE (1996) Synovial fibroblasts of patients with rheumatoid arthritis attach to and invade normal human cartilage when engrafted into SCID mice. Am J Pathol 149:1607-1615

7. Gong T, Liu L, Jiang W, Zhou R (2020) DAMP-sensing receptors in sterile inflammation and inflammatory diseases. Nat Rev Immunol 20:95-112

8. Moon SJ, Park MK, Oh HJ, Lee SY, Kwok SK, Cho ML, Ju HY, Park KS, Kim HY, Park SH (2010) Engagement of Toll-like receptor 3 induces vascular endothelial growth factor and interleukin-8 in human rheumatoid synovial fibroblasts. Korean J Int Med 25:429-425

9. Lee EY, Lee ZH, Song YW (2009) CXCL10 and autoimmune diseases. Autoimmun Rev 8:379-383

10. Fanlei H, Yingni L, Li Z (2014) Toll-like receptors expressed by synovial fibroblasts perpetuate Th1 and th 17 cell responses in rheumatoid arthritis. PLoS One 9(6):e100266. https://doi. org/10.1371/journal.pone.0100266

11. Brentano F, Schorr O, Gay RE, Gay S, Kyburz D (2005) RNA released from necrotic synovial fluid cells activates rheumatoid arthritis synovial fibroblasts via Toll-like receptor 3. Arthritis Rheum 59:2656-2665

12. Kang DC, Gopalkrishnan RV, Wu Q, Jankowsky EJ, Pyle AM, Fisher PB (2002) Mda-5: an interferon-inducible putative RNA helicase with double-stranded RNA-dependent ATPase activity and melanoma growth-suppressive properties. Proc Natl Acad Sci USA 99:637-642

13. del Toro DY, Wu B, Hur S (2015) MDA5-filament, dynamics and disease. Curr Opin Virol 12:20-25

14. Yoneyama M, Kikuchi M, Matsumoto K, Imaizumi T, Miyagishi M, Taira K, Foy E, Loo YM, Gale M Jr, Akira S, Yonehara S, Kato A, Fujita T (2005) Shared and unique functions of the DExD/H-box helicases RIG-I, MDA5 and LGP2 in antiviral innate immunity. J Immunol 175:2851-2858 
15. Imaizumi T, Aizawa-Yashiro T, Matsumiya T, Yoshida H, Watanabe S, Tsuruga K, Tatsuta T, Xing F, Hayakari R, Meng P, Tanaka H (2013) Interaction between interferon-stimulated gene 56 and melanoma differentiation-associated gene 5 in Toll-like receptor 3 signaling in normal human mesangial cells. Am J Nephrol 37:118-125

16. Franssila R, Hedman K (2006) Infection and musculoskeletal conditions: viral causes of arthritis. Best Pract Res Clin Rheumatol 20:1139-1157

17. Bokarewa M, Tarkowski A, Lind M (2008) Arthritogenic dsRNA is present in synovial fluid from rheumatoid arthritis patients with an erosive disease course. Eur J Immunol 38:3237-3244

18. Rotondi M, Minelli R, Magri F, Leporati P, Romagnani P, Baroni MC, Delsignore R, Serio M, Chiovato L (2007) Serum CXCL10 levels and occurrence of thyroid dysfunction in patients treated with interferon-alpha therapy for hepatitis $\mathrm{C}$ virus-related hepatitis. Eur J Endocrinol 156:409-414

19. Luster AD, Ravetch JV (1987) Biochemical characterization of a gamma interferon-inducible cytokine (IP-10). J Exp Med 166:1084-1097

20. Hanaoka R, Kasama T, Muramatsu M, Yojima N, Shiozawa S, Miwa Y, Negishi M, Ide H, Miyaoka H, Uchida H, Adachi M (2003) A novel mechanism for the regulation of IFN- $\gamma$ inducible protein-10 expression in rheumatoid arthritis. Arthritis Res Ther 5:R74-R81

21. Sucur A, Jajic Z, Artukovic M, Matijasevic MI, Anic B, Flegar D, Markotic A, Kelava T, Ivcevic S, Kovacic N, Katavic V, Grcevic D (2017) Chemokine signals are crucial for enhanced homing and differentiation of circulating osteoclast progenitor cells. Arthritis Res Ther 19:142

22. Yukawa K, Mokuda S, Kohno H, Oi K, Kuranobu T, Tokunaga T, Yoshida Y, Yamada J, Iwahashi M, Hirata S, Yamada S, Eiji S (2020) Serum CXCL10 levels are associated with better responses to abatacept treatment of rheumatoid arthritis. Clin Exp Rheumatol 38:956-963
23. Kwak HB, Ha H, Kim HN, Lee JH, Kim HS, Lee S, Kim HM, Kim Y, Kim HH, Song YW, Lee ZH (2008) Reciprocal cross-talk between RANKL and interferon-g-inducible protein 10 is responsible for bone-erosive experimental arthritis. Arthritis Rheum 58:1332-1342

24. Yellin M, Paliienko I, Balanescu A, Ter-Vartanian S, Tseluyko V, Xu LA, Tao X, Cardarelli PM, Leblanc H, Nichol G, Ancuta C, Chirieac R, Luo A (2012) A Phase II, randomized, doubleblind, placebo-controlled study evaluating the efficacy and safety of MDX-1100, a fully human anti-CXCL10 monoclonal antibody, in combination with methotrexate in patients with rheumatoid arthritis. Arthritis Rheum 64:1730-1739

25. Toyoda Y, Tabata S, Kishi J, Kuramoto T, Mitsuhashi A, Saijo A, Kawano H, Goto H, Aono Y, Hanabuchi M, Horikawa H, Nakajima T, Furukawa T, Sone S, Skiyama S, Nishioka Y (2014) Thymidine phosphorylase regulates the expression of CXCL10 in rheumatoid arthritis fibroblast-like synoviocytes. Arthritis Rheum 66:560-568

26. Imaizumi $T$, Arai A, Kawaguchi S, Hayakari R, Matsumiya $T$, Seya K, Yoshida H, Tanaka H (2018) Retinoic acid-inducible gene-I, melanoma differentiation-associated gene 5 and CXCL10 are induced by a TLR3 agonist in human brain microvascular endothelial cells. Clin Exp Neuroimmunol 9:189-197

27. Kawaguchi S, Sakuraba H, Haga T, Matsumiya T, Seya K, Endo T, Sawada N, Iino C, Kikuchi H, Hiraga H, Fukuda S, Imaizumi $\mathrm{T}$ (2019) Melanoma differentiation-associated gene 5 positively modulates TNF-a-induced CXCL10 expression in cultured HuH-7 and HLE cells. Inflammation 42:2095-2104

28. Tak PP (2004) IFN-beta in rheumatoid arthritis. Front Biosci 9:3242-3247

Publisher's Note Springer Nature remains neutral with regard to jurisdictional claims in published maps and institutional affiliations. 